\title{
HUBUNGAN POLA ASUH ORANG TUA DENGAN STATUS PERSONAL HYGIENE PADA ANAK RETARDASI MENTAL (Studi di SDLB Pangkalan Bun)
}

\author{
Dita Melisa $^{1}$ Rahaju Ningtyas $^{2}$ Eny Lestari $^{3}$ \\ ${ }^{1}$ STIKes Insan Cendekia Medika Jombang ${ }^{23}$ STIKes Borneo Cendekia Medika \\ Pangkalan Bun \\ ${ }^{1}$ email : ditamelisa@gmail.com, ${ }^{2}$ email : ningtyasrahaju@ gmail.com, ${ }^{3}$ email : \\ enylestari@gmail.com
}

\begin{abstract}
ABSTRAK
Pendahuluan: Retardasi mental menjadi suatu masalah karena suatu keadaan individu dengan intelegensia yang mengalami kekurangan sejak masa perkembangan (sejak lahir atau sejak masa anak-anak). Pada anak yang mengalami retardasi mental terdapat beberapa kelemahan dalam kehidupan sehari-hari seperti personal hygiene. Pola asuh orang tua memiliki peranan penting dalam pembentukan kemandirian pada anak dengan keadaan retardasi mental.Pengambilan tujuan dar penelitian ini adalah untuk menganalisis hubungan pola asuh orang tua dengan status personal hygiene pada anak retardasi mental di SDLB Pangkalan Bun. Metode: Penelitian ini menggunakan description cross sectional. Populasi dalam penelitian ini adalah orang tua murid di SDLB Pangkalan Bun yang berjumlah 43 orang. Tekhnik sampling yang digunakan adalah Total sampling, sedangkan tekhnik analisis data menggunakan analisis chi square. Instrumen penelitian menggunakankuesioner. Kuesionerdigunakan untuk variabel pola asuh orang tua dan personal hygiene anak retardasi mental. Hasil: data yang telah dilakukan dengan menggunakan uji Chi Square didapatkan hasil Sebagian besar personal hygiene anak retardasi mental baik yang menggunakan pola asuh demokratis sebanyak 23 orang $(53,3 \%)$. Selain itu didapatkan hasil uji chi square 0,000 menunjukannilai sig $p \leq \alpha(0,05)$ dengan bantuan aplikasi SPSS 16 sehingga Ho ditolak dan HI diterima. Kesimpulan: dari penelitian yang telah dilaksanakan berupa ada hubungan signifikan antara pola asuh orang tua dengan personal hygiene anak retardasi mental di SDLB Pangkalan Bun.
\end{abstract}

Kata kunci : Personal hygiene, Retardasi Mental

\section{THE RELATIONSHIP OF PARENTING PATTERN WITH PERSONAL HYGIENE STATUS IN CHILDREN MENTAL RETARDATION (Study at SDLB Pangkalan Bun)}

\begin{abstract}
Introduction :Mental retardation becomes a problem because of an individual situation with intelligence that has experienced deficiencies since the development period (from birth or since childhood). In children who have mental retardation there are some weaknesses in everyday life such as personal hygiene. Parenting patterns of parents have an important role in the formation of independence in children with mental retardation state. The purpose of this research is to analyze the
\end{abstract}


relationship of parenting pattern with the personal hygiene status in the child of mental retardation in SDLB Pangkalan Bun. Method: This study uses cross sectional description. The population in this study were parents of SDLB Pangkalan Bun, amounting to 43 people. Sampling technique used is Total sampling, while the technique of data analysis using chi square analysis. The research instrument used questionnaire. Questionnaires are used for parental parenting variables and personal hygiene of mentally retarded children. Result of data that have been done by using Chi Square test got result Most of personal hygiene child of mental retardation good that use democratic parenting as many as 23 people (53,3\%). Result: In addition, the results obtained chi square 0.000 test shows the value of sig $p \leq \alpha(0.05)$ with the help of SPSS 16 application so Ho is rejected and HI accepted. Conclusion: the conclusion of the research that has been conducted in the form of a significant relationship between parenting pattern with personal hygiene child mental retardation in SDLB Pangkalan Bun.

\section{Keywords: Personal hygiene, Mental Retardation}

\section{PENDAHULUAN}

Retardasi mental menjadi suatu masalah karena suatu keadaan individu dengan intelegensia yang mengalami kekurangan sejak masa perkembangan (sejak lahir atau sejak masa anak-anak). Pada anak yang mengalami retardasi mental terdapat beberapa kelemahan dalam kehidupan sehari-hari seperti personal hygiene. Pola asuh orang tua memiliki peranan penting dalam pembentukan kemandirian pada anak dengan keadaan retardasi mental.

Data yang dipeoleh dari (BKKBN, 2015, 43), dimana angkapeningkatan anak berkebutuhan khusus di Indonesia jumlahnya sangat besar yang mencapai 4,2 juta anak. Di Indonesia terdapat 1.713 (SLB) di seluruh provinsi yang ada di Indonesia. (KemenDikBud, 2018, 22)terdapat 23 sekolah yang terdiri dari 894 peserta didik di Kalimantan Tengah, dan salah satunya yang berada di kabupaten Kotawaringin Barat yang memiliki 1 Sekolah Dasar Luar Biasa (SDLB) yang terdiri dari 60 peserta didik. Berdasarkan hasil studi pendahuluan pada tanggal 23 maret 2018 yang dilakukan dengan cara wawancara secara lansdsung pada 10 responden yang mempunyai anak dengan masalah retardasi mental didapatkan hasil, 4 anak mampu melaksanakan personal hygiene secara benar dan madiri, 6 orang tua mengatakan anaknya tidak dapat melakukan personal hygiene karena belum diajarkan.

Penyebab seaorang anak dengan keadaan retardasi mental mengalami permasalahan mengenai atau berkenaan dengan kemampuan melakukan personal hygiene adalah bagaimana pola asuh yang diberikan oleh orang tua terutam seoarng ibu yang mengasuhnya. Dampak yang ditimbulkan jika seoarang ibu belum memiliki pengetahuan bagaimana pola asuh dengan masalah anak dengan keterbatasan mengenai personal hygiene adalah timbulnya masalah kebersihan diri sang anak(Muhammad, 2013 dalam Muntazia, 2015, 3).

Upaya penatalaksaan berkaitan dengan masalah yang telah dijabarkan, peneliti 
tertarik melakukan pengkajian secara menyeluruh dan mendalam. Oleh karena itu, peneliti ingin menganalisis secara berkelanjutan dengan mengampil penelitian tentang "Hubungan Pola Asuh Orang Tua dengan Status Personal Hygiene Pada Anak Retardasi Mental di SDLB Pangkalan Bun"

\section{METODE PENELITIAN}

Penelitian ini berjenis analitik korelasi menggunakan pendekatan description cross sectional. Populasi dalam penelitian ini adalah orang tua murid di SDLB Pangkalan Bun yang berjumlah 43 orang. Tekhnik sampling yang digunakan adalah Total sampling(menggunakan sampel secara keseluruhan),sedangkan tekhnik analisis data menggunakan analisis chi square(Sugiyono, 2013, 89).

Instrumen yang digunakan oleh penelitian berupa lembar kuesioner. Kuesionerdigunakan untuk variabel pola asuh orang tua dan personal hygiene anak retardasi mental.

\section{HASIL PENELITIAN Data Umum}

Tabel 1 distribusi frekuensi berdasarkan jenis kelamin orang tua di SDLB Pangkalan Bun Tahun 2018 perempuan dengan jumlah 28 orang $(65,1 \%)$.

Tabel 2 distribusi frekuensi berdasarkan umur orang tua di SDLB Pangkalan Bun Tahun 2018

\begin{tabular}{ccc}
\hline Umur (Tahun) & Jumlah & $\begin{array}{c}\text { Persentase } \\
(\mathbf{\%})\end{array}$ \\
\hline $20-30$ & 7 & 16,3 \\
$31-40$ & 25 & 58,1 \\
$41-50$ & 11 & 25,6 \\
\hline Total & 43 & 100 \\
\hline Sumber : data primer & &
\end{tabular}

Tabel 2 didapatkan hasil penelitiansebagian besar umur orang tua di SDLB Pangkalan Bun adalah 3140 tahun dengan jumlah 25 orang $(58,1 \%)$.

Tabel 3 Distribusi frekuensi berdasarkan tingkat pendidikan orang tua di SDLB Pangkalan Bun Tahun 2018

\begin{tabular}{ccc}
\hline Pendidikan & Jumlah & $\begin{array}{c}\text { Persentase } \\
(\mathbf{\%})\end{array}$ \\
\hline Tidak sekolah & 0 & 0 \\
\hline SD & 0 & 0 \\
\hline SMP & 4 & 9,3 \\
\hline SMA & 29 & 67,4 \\
\hline PT & 10 & 23,3 \\
\hline Total & 43 & 100 \\
\hline
\end{tabular}

Sumber : data primer

Tabel 3 didapatkan hasil penelitian sebagian besar tingkat pendidikan terakhir responden SMA sebanyak 29 responden $(67,4 \%)$.

Tabel 4 Distribusi frekuensi berdasarkan pekerjaan orang tua di SDLB Pangkalan Bun Tahun 2018

\begin{tabular}{|c|c|c|c|c|c|}
\hline Jenis kelamin & Jumlah & $\begin{array}{c}\text { Persentase } \\
(\%)\end{array}$ & \multicolumn{3}{|c|}{ SDLB Pangkalan Bun Tahun 2018} \\
\hline Laki-laki & 15 & 34,9 & \multirow{3}{*}{ Pekerjaan } & & \\
\hline Perempuan & 28 & 65,1 & & \multirow{2}{*}{ Jumlah } & \multirow{2}{*}{$\begin{array}{l}\text { Persentase } \\
(\%)\end{array}$} \\
\hline Total & 43 & 100 & & & \\
\hline \multicolumn{3}{|l|}{ Sumber : data primer } & $\begin{array}{l}\text { Buruh } \\
\text { Swasta }\end{array}$ & $\begin{array}{c}3 \\
12\end{array}$ & $\begin{array}{c}7,0 \\
27,9\end{array}$ \\
\hline \multirow{4}{*}{\multicolumn{3}{|c|}{$\begin{array}{l}\text { Tabel } 1 \text { didapatkan hasil penelitian } \\
\text { sebagian besar jenis kelamin orang tua } \\
\text { murid di SDLB Pangkalan Bun adalah }\end{array}$}} & Wiraswasta & 3 & 7,0 \\
\hline & & & PNS, TNI/POLRI & 8 & 18,6 \\
\hline & & & Ibu Rumah Tangga & 17 & 39,5 \\
\hline & & & Total & 43 & 100 \\
\hline
\end{tabular}


Sumber : data primer

Tabel 4 didapakan hasil penelitian hampir seluruhnya pekerjaan orang tua di SDLB Pangkalan Bun adalah Ibu rumah tangga dengan jumlah 17 orang $(39,3 \%)$.

\section{Data Khusus}

Tabel 5 Karakteristik responden berdasarkan pola asuh orang tua

\begin{tabular}{ccc}
\hline Pola Asuh & Jumlah & $\begin{array}{c}\text { Persentase } \\
(\mathbf{\%})\end{array}$ \\
Otoriter & 14 & 32,6 \\
Permisif & 4 & 9,3 \\
Demokratis & 25 & 58,1 \\
\hline Total & 43 & 100 \\
\hline
\end{tabular}

Sumber : data primer

Tabel 5 didapatkan hasil penelitian sebagian besar pola asuh orang tua di SDLB Pangkalan Bun adalah demokratis dengan jumlah 25 orang $(58,1 \%)$.

Tabel 6 Karakteristik responden berdasarkan personal hygiene anak retardasi mental

\begin{tabular}{ccc}
\hline $\begin{array}{c}\text { Personal } \\
\text { Hygiene }\end{array}$ & Jumlah & $\begin{array}{c}\text { Persentase } \\
(\boldsymbol{\%})\end{array}$ \\
Baik & 27 & 62,8 \\
Cukup & 9 & 20,9 \\
Kurang & 7 & 16,3 \\
\hline Total & 43 & 100 \\
\hline
\end{tabular}

Sumber : data primer

Tabel 6 didapatkan hasil penelitian sebagian besar personal hygiene anak retardasi mental di SDLB Pangkalan Bun adalah baik dengan jumlah 27 orang $(62,8 \%)$.

Tabel 7 Karakteristik responden berdasrkan tabulasi silang hubungan pola asuh dengan personal hygiene pada anak retardasi mental

\begin{tabular}{|c|c|c|c|c|c|c|}
\hline & \multicolumn{6}{|c|}{$\begin{array}{c}\text { Pola asuh } * \text { Personal Hygiene } \\
\text { Crosstabulation }\end{array}$} \\
\hline & & & \multicolumn{3}{|c|}{ Personal Hygiene } & \multirow{2}{*}{ Total } \\
\hline & & & Baik & Cuku & Kura & \\
\hline \multirow[t]{6}{*}{$\begin{array}{l}\text { Pola } \\
\text { asuh }\end{array}$} & $\begin{array}{l}\text { Oto } \\
\text { rite }\end{array}$ & $\begin{array}{l}\text { Coun } \\
\mathrm{t}\end{array}$ & 5 & 6 & 1 & 12 \\
\hline & $\mathrm{r}$ & $\begin{array}{l}\% \text { of } \\
\text { Total }\end{array}$ & $11.6 \%$ & $\begin{array}{r}14.0 \\
\%\end{array}$ & $2.3 \%$ & $\begin{array}{l}27 . \\
9 \%\end{array}$ \\
\hline & $\begin{array}{l}\text { Per } \\
\text { mis }\end{array}$ & $\begin{array}{l}\text { Coun } \\
t\end{array}$ & 0 & 1 & & 6 \\
\hline & if & $\begin{array}{l}\% \text { of } \\
\text { Total }\end{array}$ & $.0 \%$ & $2.3 \%$ & $\begin{array}{r}11.6 \\
\%\end{array}$ & $\begin{array}{l}14 . \\
0 \%\end{array}$ \\
\hline & $\begin{array}{l}\text { De } \\
\text { mo }\end{array}$ & $\begin{array}{l}\text { Coun } \\
t\end{array}$ & 23 & 2 & 0 & 25 \\
\hline & $\begin{array}{l}\text { krat } \\
\text { is }\end{array}$ & $\begin{array}{l}\% \text { of } \\
\text { Total }\end{array}$ & $53.5 \%$ & $4.7 \%$ & $.0 \%$ & $58.1 \%$ \\
\hline \multirow[t]{2}{*}{ Total } & & $\begin{array}{l}\text { Coun } \\
t\end{array}$ & 28 & 9 & & 43 \\
\hline & & $\begin{array}{l}\% \text { of } \\
\text { Total }\end{array}$ & $65.1 \%$ & $\begin{array}{r}20.9 \\
\%\end{array}$ & $\begin{array}{r}14.0 \\
\%\end{array}$ & $\begin{array}{r}100.0 \\
\%\end{array}$ \\
\hline
\end{tabular}

Tabel 7 tersaji bahwa sebagian besar personal hygiene anak retardasi mental adalah baik yang menggunakan pola asuh demokratis sebanyak 23 orang $(53,5 \%)$. Selain itu, hasil uji chi square didapatkan $(p)=0,000$ dimana nilai $\alpha$ yang ditetapkan $(\alpha=0,05)$ dengan bantuan SPSS 16 sehingga Ho ditolak HI diterima maka dapat dikatakan hipotesis peneliti terbukti kebenarannya.

\section{PEMBAHASAN}

Pola asuh orang tua di SDLB Pangkalan Bun

Tabel 5 didapatkan hasil penelitian sebagian besar pola asuh orang tua di SDLB Pangkalan Bun adalah 
demokratis dengan jumlah 25 orang $(58,1 \%)$.

Peneliti berpendapat bahwa hasil yang berkenaan dengan pola asuh orang tua sudah dalam tahan dan perkembangan yang cukup baik. Banyak faktor yang mempengaruhi pola asuh terhadap anak yang mengalami retardasi menal salah saunya adalah perlakuan erhadap anak, mendidik, dan membimbing.

Menurut (Casmini, 2007, 37), bahwa bagaimana seoarang pengasuh dalam melakukan pola asuh harusnya memperlakukan anak harus sesuai dengan perlakuan yang sesuai, mendidik, seta membimbingnya agar tujuan dalam menghasilkan kriteria seorang anak yang memiliki suatu pemahaman tentang norma-norma yang diperlakukan dimasyarakat unuk ditaati..

\section{Status personal hygiene pada anak retardasi mental di SDLB Pangkalan Bun}

Tabel 6 didapatkan hasil penelitian sebagian besar personal hygiene anak retardasi mental di SDLB Pangkalan Bun adalah baik dengan jumlah 27 orang $(62,8 \%)$.

Peneliti berpendapat bahwa hasil yang telah disajikan dapat dijadikan patokan bahwa pola asuh sudah memiliki dalam kondisi yang sesuai. pemahan dalam masalah personal hygienesudah banyak cara mengatasinya.

Hal ini sesuai pendapat (Isro'in \& Andarmoyo, 2012, 44), personal hygiene dikatan sebagai suatu pengetian sehat perorangan, keadaan seseorang dikatan dapat menjaga kebersihan dirinya setalah mendapatkan motivasi yang didapatkan dari berbagai sumber.

Hubungan pola asuh orang tua dengan status personal hygiene pada anak retardasi mental di SDLB Pangkalan Bun

Tabel 7 tersaji bahwa sebagian besar personal hygiene anak retardasi mental adalah baik yang menggunakan pola asuh demokratis sebanyak 23 orang $(53,5 \%)$. Selain itu, hasil uji chi square didapatkan $(p)=0,000$.

Peneliti berpendapat dimana kondisi tentang hubungan pola asuh orang tua akan memiliki dampak terhadap terciptanya kemampuan anak melakukan personal hygiene dalam merawat kondidsi dirinya. Aanak dengan kondisi retardasi mental sangatlah memerlukan perhatian yang lebih dari anak nornal biasanya.

Hal ini sesuai pendapat (Nurmaini, 2014, 4), pemeberian pola asuh yang bersifat demokratis akan memiliki dampak yang banyak positifnya. Seorang pengasuh (orang tua) yang melakukan pendidikan dengan cara demkratis akan mnimbulkan sifat karakterisnya dengan kepribadian yang baik dan mampu mengatasi masalah dengan cara yang diambil melalui pemikiran dan kemampuan saling menerima hasil demi tercapainya haisl yang diinginkan.

\section{KESIMPULAN DAN SARAN}

\section{Kesimpulan}

1. Pola asuh orang tua sebagian besar di SDLB Pangkalan Bun adalah demokratis dengan jumlah 25 orang $(58,1 \%)$. 
2. Status personal hygiene anak retardasi mental hampir seluruhnya di SDLB Pangkalan Bun baikdengan jumlah 27 orang $(62,8)$.

3. Ada hubungan pola asuh orang tua dengan status personal hygiene anak retardasi mental di SDLB Pangkalan Bun mendapatkan nilai $(p)=0,000$.

\section{Saran}

1. Bagi Tenaga Pendidik SDLB

Bagi tenaga pendidik SDLB, di harapkan dapat lebih menjalin kerjasama dalam menjalin hubungan terhadap orang tua yang memiliki anak dengan retardasi mental. Acuan pemberian pendidikan dalam menerapkan pola asuh yang tepat, penuh kasih sayang serta perhatian yang lebih pada anak saat dirumah terutama dalam masalah personal hygiene agar dapat mengoptimalkan kemampuan yang ada pada diri anak.

2. Bagi Institusi Pendidikan ICME

Bagi institusi pendidikan ICME, berdasarkan hasil penelitian ini diharapkan dapat menjadi wawasan tambahan ilmu pengetahuan tentang keperawatan anak khususnya tentang pola asuh orang tua dan personal hygiene pada anak retardasi mental agar dapat meningkatkan kesehatan pada anak menjadi lebih baik.

3. Bagi Peneliti selanjutnya

Diharapkan para peneliti berikutnya dapat melaksanakan penelitian yang sama dengan menggunakan variabel yang berbeda untuk menunjang terciptanya penelitian yang lebih baik dan dapat dijadikan pembelajaran terhadap permasalahan yang telah diteliti sebelumnya.

\section{DAFTAR PUSTAKA}

BKKBN, Jumlah Anak Berkebutuhan KhususTerus

Meningkathttp://www.merries.co.i d/toddler/jumlah-anakberkebutuhan-khusus-terusmeningkatdi akses pada 12 maret 2018

Casmini. 2007. Emotional Parenting. Yogyakarta : Nuansa Aksara.

Isro'in \& Andarmoyo. 2012. Personal Hygiene ; Konsep, Proses dan Aplikasi dalam Praktik Keperawatan, Edisi Pertama. Yogyakarta : Graha Ilmu.

Kementerian Pendidikan dan Kebudayaan. 2018. Data Pokok Pendidikan Dasar dan Menengah, Direktorat Jenderal Pendidikan Dasar dan Menengah, Kementerian Pendidikan dan Kebudayaan.http://dapo.dikdasme n.kemdikbud.go.id/sp di akses pada 6 Maret 2018

Muntazia, Dina. A. 2015.Kaitan Antara Pola Asuh Permisif dengan Perilaku Asertif. Universitas Muhammadiyah Surakarta.

Nurmaini, Risa Dwi. 2014. Hubungan Pola Asuh Orang Tua dengan Kemampuan Personal Hygiene pada Anak Retardasi Mental di SDLB Kabupaten Jember. Universitas Muhammadiyah Jember.

Sugiyono. 2013. Metode Penelitian Pendidikan Pendekatan Kuantiattif, Kualitatif dan $R \& D$. Bnadung : ALFABETA. 